Case Report

\title{
Low Grade Endometrial Stromal Sarcoma : Report of a Rare Uterine Malignancy
}

\author{
Harish Shetty ${ }^{1}$, Prasanna Kumar Shetty K. ${ }^{2}$, Aparna Rajesh ${ }^{3}$ \& Spandana J.C. ${ }^{4}$ \\ ${ }^{1}$ Professor $\&$ HOD, ${ }^{2}$ Professor, ${ }^{3}$ Associate Professor, ${ }^{4}$ Postgraduate \\ Department of Obstetrics \& Gynecology, K.S. Hegde M edical Academy, Nitte University, M angalore, Karnataka, India. \\ Correspondence \\ Spandana J.C. \\ Postgraduate, Department of Obstetrics \& Gynecology, K.S.Hegde M edical Academy, Nitte University, M angalore - 575018. \\ Mobile : +919964611581 E-mail : drspanjc@gmail.com
}

\begin{abstract}
Endometrial stromal sarcoma (ESS) is a rare malignant tumor, occurring in the age group of $40-50$ years. We report a case of lowgrade ESS in a 42 year old women, presenting as rapid enlargement of uterus associated with excessive vaginal bleeding. ESS can be mistaken for leiomyoma. Histopathological examination remains the mainstay for diagnosis of such tumors. Although rare, ESS should be considered in the differential diagnosis of all women who present with a rapid enlargement of a uterine leiomyoma.
\end{abstract}

Keywords : endometrial stromal sarcoma, perimenopausal, menorrhagia, leiomyoma.

\section{Introduction}

Low-grade endometrial stromal sarcoma(LGESS), also known as endolymphatic stromal myolysis, is a rare tumor, accounting for just $0.2 \%$ of malignant uterine tumors and approximately $10 \%$ to $30 \%$ of uterine sarcomas(1-3). They resemble endometrialstromal cells in the proliferative stage. The annual incidence of endometrial stromal sarcoma(ESS) is 1-2 per million women. Compared to other uterine malignancies, ESS affects younger women and the mean age is $42-58$ years( 4 ).

Based on the mitotic state, ESS is histologically divided into two groups: high grade(HG) and low grade(LG)(5). HGESS is currently defined as an undifferentiated endometrial sarcoma(UES) characterized by more than 10 mitosis per 10 high power fields(HPFs). Additionally, this sarcoma is more aggressive and has a poor prognosis. In contrast, LGESS has fewer than 10 mitosis per $10 \mathrm{HPFs}$, and the cell

\begin{tabular}{|c|}
\hline Access this article online \\
\hline Quick Response Code \\
\hline
\end{tabular}

nuclei are not atypical or pleomorphic(5). LGESS is relatively more common and tends to occur before menopause. LGESS exhibits a more indolent course, but has high relapse potential(6). These two entities should be treated differently.

For LGESS, hysterectomy is the cornerstone of treatment, however, the role of a bilateral salpingooophorectomy(BSO), as well as lymphadenectomy for complete surgical staging, is debated. Adjuvent treatment including hormonal treatment, chemotherapy and radiotherapy(7).

Recently a specific translocation $\mathrm{t}(7 ; 17)(\mathrm{p} 15 ; \mathrm{q} 21)$ with involvement of two zinc finger genes juxtraposed with

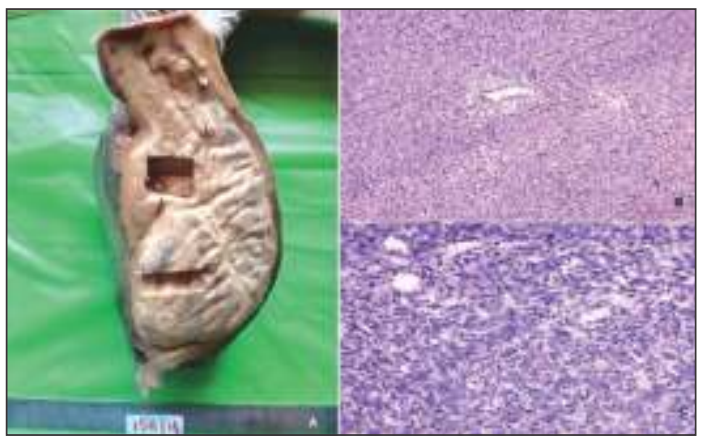

Fig. 1 A : Gross photograph showing a cut section of the uterus with a large partially circumscribed grey white tumor obliterating the endometrial cavity.

Fig. 2 B: Low power microphotograph displaying highly cellular tumor comprising of oval to spindle cells supported by rich vascular network ( $\mathrm{H} \&$ Estain X5X)

Fig. 2 C: High power microphotograph displaying tumor cells displaying mild to moderate pleomorphism having close proximity to the wall of proliferating blood vessels ( $H \& E$ stain $\mathrm{X} 40 \mathrm{x}$ ) 
another zinc finger protein 1 and joint juxtraposed with another zinc finger protein 1 was described in most of the ESS(8). There is relation between chromosomal aberrations and endometrial sarcomas. Chromosomal deletion on 7p was the most common finding $(55.6 \%)$ in ESS and may play a role in tumor development and progression(9).

\section{Case Report}

A 42 years old female (para3 living3) was admitted to our hospital with complaints of menorrhagia and mild lower abdominal pain for the last 2 years. Her menstrual cycles had been normal six months back when she developed menorrhagia. She had periods at an interval of twenty five days and bleeding lasting for eight to ten days. Flow was excessive with history of passage of clots.

She was not using any contraception. There was neither history of exogenous hormone use nor history of drug intake like tamoxifen.

Physical examination showed the patient was moderately built and nourished with severe pallor. The rest of the general and systemic examination was normal. Her haemoglobin was $7 \mathrm{gm} \%$.

On per abdominal examination there was suprapubic mass corresponding to twenty eight weeks size uterus. On per speculum examination cervix was healthy. On pervaginal examination uterus was uniformly enlarged to twenty eight weeks size, soft to hard in consistency and mobile. Bilateral forniceswere free.

Ultrasound showed grossly enlarged uterus $>25 \times 10 \mathrm{X}$ $15 \mathrm{~cm}$ and multiple hypoechoic masses largest measuring $12 \mathrm{~cm}$ in the uterus suggestive of fibroids. Our clinical diagnosis was fibroid uterus with cystic degenerative changes. Prior to surgery she was transfused with two units of blood. Total abdominal hysterectomy and bilateral salpingo-oophorectomy was performed.

Intraoperative uterus was enlarged to twenty eight weeks size with irregular surface and soft in consistency, with cervix. Bilateral ovaries were normal. Cut section of the uterus showed a mass $10 \times 12 \mathrm{~cm}$ a large partially circumscribed grey white tumor obliterating the endometrial cavity with fluid filled cystic spaces histopathological examination of the specimen showed low grade endometrial stromal sarcoma.

The histopathological diagnosis of LGESS was conferred for appropriate treatment. Immunohistochemical stains were not done in our case because of economic limitations. Postoperative period was uneventful. She received adjuvent pelvic radiotherapy(2DRT)with 50Gy for 25 days.

\section{Discussion}

Uterine sarcomas are rare tumours of mesoderaml origin. They constitute 2 to $6 \%$ of uterine malignancies. Of these, endometrial stromal sarcomas are very rare.

They are divided into three types depending upon mitotic activity, vascular invasion and observed differences in prognosis.

1. Endometrial stromal nodule(ESN)

2. Low grade endometrial stromal sarcoma(ESS) and

3. High grade or undifferentiated endometrial stromal sarcoma(UES)(10)

Boardman et al. differentiated low grade ESS by cellular uniformity, less frequent mitosis( $<3 / 10 \mathrm{HPF}$ versus $>10 / \mathrm{HPF}$ ), and lack of haemorrhage and necrosis(11).

Uterine sarcomas usually affect post-menopausal females. Women with LGESS are younger with a median age being 45 and 57 years. Symptoms at presentation include abnormal vaginal bleeding, menorrhagia and abdominal pain(12). The tumours have an indolent growth with a tendency for late recurrence(13). Metastasis are rarely detected before the diagnosis of the primary lesion.(14).

Grossly, low grade ESSs involve the endometrium, occasionally extensively. By definition tumours are infilterative. Rarely, the tumours manifest as polyps, usually with haemorrhage and infarction. Because of its 
prominent intravascular growth a soft tan to yellow cut surface and appear as cords and nodules infilterating through the uterine smooth muscle.

The histologic features recapitulate the gross appearance with cords of tumour cells infilterating between smooth muscle and within lymphatic spaces. The neoplastic stromal cells resemble those of the proliferating endometrium, are monotonous in appearance, and have relatively uniform size and shape(14). Tumour cell nuclei are round to ovoid and have fine chromatin, and small, inconspicuous nucleoli may be seen. A small amount of cytoplasm is present, and cell borders are indistinct. M itotic activity is usually low $(<10 / 10 \mathrm{HPF})$. It should be noted that rare causes of low-grade ESS will have a greater number of mitotic figures, although this is not associated with an adverse prognosis(15). Proliferating small vessels resembling the endometrial spiral arterioles are characteristic, and tumours can have bands of hyaline connective tissue separating islands and clusters of bland neoplastic stromal cells(16).

The differential diagnosis of LGESS includes ESN, cellular leiomyoma, cellular intravenous leiomyomatosis, cellular endometrial polyp and various soft tissue neoplasms(17)

Surgery is the final resort for primary treatment of LGESS consisting of total abdominal hysterectomy with bilateral salpingo-oophorectomy. Regardless of

\section{References}

1. Evans HL: Endometrial stromal sarcoma and poorly differentiated endometrial sarcoma. Cancer 50: 2170-2182, 1982.

2. Sorbe $B$ and Johansson B: Prophylactic pelvic irradiation as part of primary therapy in uterine sarcomas. Int J Oncol32: 1111-1117, 2008.

3. Yoney A, Eren B, Eskici S, Salman A and Unsal M : Retrospective analysis of 105 cases with uterine sarcoma. Bull Cancer 95: E10-17, 2008.

4. Tavassoli FA, Devilee P, WHO classification of pathology and genetics of tumours of the breast and female genital organs. In Tavasssoli FA, Devilee P, editors, Lyon, France: IARC press; 2003. p. 233-236.

5. Norris HJ, Taylor HB. M esenchymal tumours of the uterus. I. A clinical and pathological study of 53 endometrial stromal tumors. Cancer 1966; 19: 755-766

6. Gadducci A, Cosio S, Romanini A, Genazzani AR. The management of patients with uterine sarcoma: a debated clinical challenge. Crit rev oncolHematol 2008;65: 129-242.

7. Dos Santos LA, Garg K Diaz JP, Soslow RA, Hensley ML, Alekttiar KM. incidence of LN and adnexal metastasis in endometrial stromal patient's age, preservation of ovarian tissue because of likelyhood of ovarian metastasis. In addition, since ESS has sterioid receptors the possibility exists that estrogen production by retained ovaries may stimulate any residual disease. , oophorectomy is recommended. Due to high recurrence risk even with localized tumours. Many clinicians advocate use of adjuvant chemotherapy, radiation therapy and/or hormonal therapy to suppress tumour growth.

Hormoe therapy with medroxy-progesterone, tamoxifen, gonadotropin releasing hormone analogues $(\mathrm{GnRH})$ and aromatase inhibitors are suggested for LGESS and for recurrent disease(18). Uterine sarcomas have a poorer prognosis and survival is much worse than that reported for endometrial adenocarcinoma, with an overall survival of less than $50 \%$ at 2 years, even when presenting at an early stage. A higher survival is reported with LGESS as compared to other uterine $\operatorname{sarcoma}(19,20)$.

\section{Conclusion}

LGESS is a rare malignant tumor, presenting as abnormal uterine bleeding in perimenopausal women. The usual preoperative diagnosis is uterine leiomyoma and definitive diagnosis is achieved only after histopathology of uterus. By reporting our case, we wish to stress the necessity for a high grade suspicion to diagnose this tumor even in younger women. A prompt diagnosis and timely intervention are keys to improve patient survival.

sarcoma. gynecolOncol 2011: 121:319-322

8. Micci F, Panagopoulos I, Bjerkehagen B, Heim S. Cosistent rearrangement of chromosomal band $6 \mathrm{p} 21$ with generation of fusion genes JAZF1/PHF1 and EPC1/PHF1 in endometrial stromal sarcoma. Cancer Res2006:66:107-12.

9. Halbwed I, Ullmann R, Kremser ML, Man YG, Moud NI, Lax S. chromosomal alterations in low-grade endometrial stromal sarcoma and undifferentiated endometrial sarcoma as detected by comparative genomic hybridization. GynecolOncol 2005;2:582-7.

10. Berek JS(ed). Novaks Gynaecology $14^{\text {th }}$ edition. Philadelphia, Lippincott Williams and Wilkins. 2006:1382-84.

11. Broadman CH, Webb MJ, Jefferies JA. Low grade endometrial stromal sarcoma of the ectocervix after therapy for breast cancer. GynecolOncol 2000;79(1): 120-3.

12. Livi L, Paiar F, Shah N, Blake P, VillanucciA,Amunni G. Uterine sarcoma: twenty-seven years of experience. Int 」 Radiant OncolBiolPhys 2003;57(5):1366-73. 
13. Shafi M, Luesley DM, Jorda JA. Gynecological oncology. London, England: Churchill Livingstone; 2001: 120-121.

14. Hendrickson MR,Tavassoli FA, Kempson RL. mesenchymal tumours and related lesions. In :Tavassoli FA, Devilee P, eds. Pathology and genetics of tumours of breast and female genital organs. Lyon, France: IARC Press; 2004:233-236. World health organization classification of tumours.

15. Evans HL, Chawla SP, Simpson C. smooth muscle neoplasms of the uterus other than ordinary leiomyoma: a study of 46 cases, with emphasis on diagnostic criteria and prognostic factors. Cancer. 1988:62:2239-2247

16. Al-Nafussi Al. tumour Diagnosis: Practical approach and pattern analysis. $2^{\text {nd }}$ ed. London, England: oxford University Press;2005:424429.
17. Baker P, Olivia E. Endometrial stromal tumors of the uterus: A practical approach using conventional morphology and ancillary techniques. J ClinPathol 2007;60(3):235-43.

18. Linder T, Pink D, Kretzschmar A, M rozek A, Patience PC, Reichardt P. hormone treatment of endometrial stromal sarcomas: a possible indication for aromatase inhibitors. J ClinOncol 2005; 23: 16s:9057.

19. Husseiny GE, Bareedy NA, M ourad WA, M ohamed G, Shoukri M, Subhi J. prognostic factors and treatment modalities in uterine sarcoma. Am J ClinOncol 2002;25(3):256-60.

20. Rovirossa A, Ascaso, Ordi J, Abellana, Arenas M, Lejarcegui JA. is vascular and lymphatic space invasion a main prognostic factor in uterine neoplasms with a sarcomatous component? A retrospective study of prognostic factors of 60 patients stratified by stages. Int J Radiant OncolBiolPhys 2002;52(5):1320-9. 